\title{
Helping behaviour and parental care in fairy-wrens (Malurus)
}

\author{
Nicolas Margraf ${ }^{\mathrm{A}, \mathrm{B}}$ and Andrew Cockburn ${ }^{\mathrm{A}}$ \\ AEvolution, Ecology and Genetics, Research School of Biology, The Australian National University, \\ Canberra, ACT 0200, Australia. \\ ${ }^{B}$ Corresponding author. Email: andrew.cockburn@anu.edu.au
}

\begin{abstract}
Cooperative breeding among birds was first discovered in the genus Malurus (Maluridae), the fairy-wrens. Cooperative care arises because male, and sometimes female, offspring remain in their natal territory and help the adults rear offspring. Early uses of data from Superb Fairy-wrens (Malurus cyaneus) to illustrate how kin altruism can explain helping behaviour were based on flawed assumptions. Most importantly, high rates of extra-group mating mean that the helpers often assist adults to which they are unrelated. However, measuring the costs and benefits of altruism has also proved difficult. Helping behaviour and its outcomes among species of Malurus are surprisingly diverse, despite similar founding conditions for cooperative breeding. First, species differ in whether help provides fitness benefits, in the recipients of those benefits, and whether benefits are immediate or deferred. Second, species vary greatly in whether females are philopatric and the extent to which female auxiliaries (supernumeraries), when present, provide care. Finally, male auxiliaries are much less sensitive to the needs of the brood than females. In this review we show that these three aspects of helping behaviour lack compelling explanations. We develop hypotheses to explain each phenomenon. Distinguishing among these hypotheses will greatly enhance our understanding of the remarkable social system of Malurus, and inform the study of cooperative breeding and sexual conflict in general.
\end{abstract}

Additional keywords: cooperative breeding, extra-pair copulation, helper at the nest, kin altruism, Maluridae, sexual conflict.

Received 7 January 2013, accepted 13 June 2013, published online 15 August 2013

\section{Introduction}

Fairy-wrens in the genus Malurus have played a critical role throughout the history of the study of cooperative breeding, the form of parental care in which more than two birds cooperate to provision a single brood of young. The Superb Fairy-wren (Malurus cyaneus) was the first bird recognised to have cooperative provisioning in the $1850 \mathrm{~s}$, and helping behaviour (assistance of dominant birds in rearing young by subordinates) was the subject of an experiment as early as 1910 (Boland and Cockburn 2002). This species was also the first cooperatively breeding species for which colour-bands were used to distinguish among individuals in the 1950s (Rowley 1957, 1964; Bradley and Bradley 1958). Once the theory of kin selection provided a cohesive theoretical framework for understanding cooperative behaviour, the Superb Fairy-wren was used as a textbook example of the application of Hamilton's rule for the spread of kin altruism by Brown (1975) and Grafen (1984). The Superb Fairy-wren also provided what has become a classic case study of how constraints on independent breeding promote natal philopatry by restricting natal dispersal (Pruett-Jones and Lewis 1990).

Here we look anew at what is known of offspring provisioning in the genus Malurus. We show how studies of these species continue to inform controversies concerning the role of kinship in directed care, the benefits of differential investment in eggs by females, and the conceptual difficulties in demonstrating the benefits that arise from helping behaviour, both in the immediate term and the future. Importantly, as new species are the subject of detailed study, surprising variation between species has emerged, and we develop new hypotheses to explain the variation among species.

\section{How widespread is helping behaviour among the Maluridae?}

The distribution of cooperative breeding in the Maluridae has been reviewed by Rowley and Russell (1997), who concluded that it is likely to occur facultatively in at least some populations of all 28 species in the six genera that comprise the family (Amytornis, Chenorhamphus, Clytomyias, Malurus, Sipodotus and Stipiturus), a view with which we concur (see also Schodde and Weatherly 1982; Higgins et al. 2001; Maguire and Mulder 2004). The Maluridae are thus the largest family of birds in which all species are likely to exhibit some cooperative breeding (Cockburn 2006). Unfortunately, almost all detailed behavioural data come from the genus Malurus, and for the purposes of this review we will concentrate exclusively on that genus, which includes 11 species.

It is clear that within Malurus there is substantial betweenpopulation variation in the incidence of helping behaviour, with populations differing in the proportion of territories containing 
helpers, the maximum size of groups and, most strikingly, the extent to which females provide care.

In all species that have been well studied, the main path to recruitment of auxiliary (supernumerary) helpers is through philopatry of young born on the territory (Tidemann 1986; Russell and Rowley 1993a, 2000; Rowley and Russell 1997; Van Bael and Pruett-Jones 2000; Cockburn et al. 2008b; Kingma et al. 2010, 2011). Indeed, the proportion of young male Superb Fairy-wrens that gain a breeding vacancy on their natal territory is the highest known for birds living on year-round all-purpose territories (60\%), and Splendid (M. splendens) and Red-winged (M. elegans) Fairy-wrens are also among the five highest values ever recorded (Cockburn et al. 2008b). However, assistance by helpers can be completely absent in some populations of Superb Fairy-wrens (R. A. Mulder, pers. comm.) and Red-backed Fairywrens (M. melanocephalus; Murphy et al. 2010), although these species breed cooperatively over much of their range. In Superb Fairy-wrens, provisioning by auxiliaries in arid-zone populations can be confined to the young of first broods provisioning the second brood of the season, which is only possible when there is sufficient rainfall to extend the breeding season (Tidemann 1986). Tidemann (1986) inferred that the absence of adult helpers may be a consequence of poor recruitment in a marginal population at the edge of its range. We suggest that poor recruitment in marginal habitats may provide a general explanation for the absence of helpers in some habitats, with the population of Red-backed Fairy-wrens above rendered marginal by repeated habitat disturbance through fire.

In some populations, only auxiliary males provide care throughout the breeding season and dispersal by females from the natal territory is obligate (Cockburn et al. 2003, 2008b), although females that do not disperse until after breeding is under way can sometimes help at the early nests of the season (Rowley and Russell 1997). However, in other populations auxiliary adult females can also provide care, and in Red-winged Fairywrens, males and females are equally likely to act as helpers (Russell and Rowley 2000; Brouwer et al. 2011). This variation appears to reflect ecological conditions, as female helping appears to be most common in populations in south-western Australia (Rowley and Russell 1997). For example, in Splendid Fairy-wrens, populations near Perth show a high incidence of female help (Russell and Rowley 1993a) but, further east, help in this species is overwhelmingly male-biased (Van Bael and PruettJones 2000). The precise reasons for this geographical gradient are not clear. We hypothesise that this may be because rates of nest predation are lower in south-western Australia than elsewhere (Remeš et al. 2012), which may affect the rates of recruitment of helpers. However, this issue has not been satisfactorily explored and the gradient in female help is a problem that warrants additional investigation.

\section{What causes natal philopatry?}

Cooperative breeding is often associated with natal philopatry, or retention of young in the territory in which they hatched beyond the time they are old enough to reproduce independently. Although it is now clear that philopatry can arise in response to several selection pressures (Ekman et al. 2004), even in the same species (Komdeur 1992), a particularly influential view suggests that philopatry arises because the landscape in which the bird lives is full of territories, so there are no opportunities to breed independently elsewhere (ecological constraints hypothesis; Emlen 1982; Brown 1987). In a classic study that has been used to support this argument, Pruett-Jones and Lewis (1990) showed experimentally that, in Superb Fairy-wrens, auxiliary males fail to disperse because there are no breeding opportunities elsewhere. Removal of the male and female from a territory attracted no interest in the vacant territory from neighbouring subordinate males but when the original female was returned an auxiliary male immediately dispersed into the vacancy. This ingenious experiment proves that male dispersal is frustrated by a lack of potential mates.

However, there are difficulties with the interpretation of these findings within the traditional version of the ecological constraints hypothesis. Although the adult sex ratio is strongly biased towards males (Cockburn et al. 2008b), the number of young males and females produced and reared is only slightly biased towards males (Cockburn and Double 2008). The shortfall of female Superb Fairy-wrens with which males can attempt to breed arises because females suffer high mortality during their own attempts to disperse from their natal territory (Cockburn et al. 2003), presumably because they fail to gain a vacancy (Cockburn et al. 2003). The ecological constraints hypothesis predicts that females, like males, should not disperse to their doom (Cockburn 2013). Further difficulty arises in extending a shortfall of females to explain cooperative breeding throughout Malurus. In Red-winged Fairy-wrens, female dispersal is also absent, and so female auxiliaries are as common as males (Russell and Rowley 2000; Brouwer et al. 2011) so the constraint in Superb Fairy-wren populations does not apply in Red-winged Fairy-wrens. However, the Red-winged Fairy-wren has the highest incidence of helping behaviour in any Malurus.

Great insight would potentially be gained from repeating the experiment of Pruett-Jones and Lewis (1990) in a population of Red-winged or Splendid Fairy-wrens in which female philopatry is common. An ideal design would be to remove unassisted pairs from territories surrounded by neighbouring territories where some groups had just male helpers and others had just female helpers. In this case the creation of a vacant territory should prompt dispersal by a male and a female from different territories to form a new pair. The failure of this prediction would be very difficult for contemporary theory.

\section{Superb Fairy-wrens do not validate the kin selection hypothesis for helping}

Brown (1975) and Grafen (1984) used the Superb Fairy-wren as a textbook case study to illustrate the application of Hamilton's theory of kin selection to explain helping behaviour, which in a simple form predicts that individuals should invest in kin other than their immediate offspring when:

$$
r \mathrm{~B}>\mathrm{C}
$$

where $r$ is the coefficient of relatedness between individuals, B is the benefit to the recipient caused by the actions of the donor of the investment and $\mathrm{C}$ is the cost suffered by the donor. It is heuristically useful to examine their treatment for two reasons. First, it illustrates the ease with which we can be misled by 
simple and plausible assumptions that are undermined by detailed knowledge of natural history. Second, it helps focus attention on the care that is required to achieve meaningful empirical estimates of key parameters.

They developed parameters for this model using data from Rowley (1964), first contrasting the annual productivity of unassisted pairs (1.5 young) and trios, in which the dominant male and his mate are assisted by a single auxiliary helper (2.8 young), to estimate $\mathrm{B}=2.8-1.5=1.3$ young. In the Superb Fairy-wren, females always disperse from the natal territory and this was taken to indicate that they were dispersing once they had located a vacancy. Having taken up a vacancy the female can expect to gain at least the productivity of an unassisted pair. Foregoing this opportunity would therefore impose an equivalent cost so $\mathrm{C}_{\text {female }}=1.5$. By contrast, the failure of males to disperse was taken to indicate that there were no breeding vacancies for them, so that the costs did not differ between males foregoing reproduction by staying at home and helping and those that dispersed without any opportunity to breed independently, so $\mathrm{C}_{\text {male }}=0$.

Helpers benefit (provide B) to both the male and female on their territory, but they pay a cost (C) just once. If they are helping their mother and father, $r$ is 0.5 in each case. Hence the left side of the equation is $0.5 \mathrm{~B}+0.5 \mathrm{~B}$, which simplifies to B. $B$ is greater than $C_{\text {male }}$, so males should help, but less than $\mathrm{C}_{\text {female }}$, so females should not, which is what we observe.

Unfortunately, although retrospectively 'predicting' the behaviour it set out to explain, this parameterisation is utterly wrong, as every one of the underlying assumptions was incorrect. The first difficulty arises with respect to $r$; the estimates were shown to be wrong because extreme rates of extra-group cuckoldry mean that the subordinate makes are assisting a dominant male to which they are unrelated, and young to which neither they nor the dominant male need be related (Mulder et al. 1994; Cockburn 2013; Cockburn et al. 2013). Because turnover of the breeding females can be quite high, subordinate males are often also unrelated to the mother, and hence provision young to which they are completely unrelated, so $r$ is again often zero (Dunn et al. 1995).

The second difficulty arises with respect to estimates of C. As we have described above, many females die in the attempt to find a mate, and it is this mortality during dispersal that causes males to be over-represented in the adult population (Cockburn et al. 2003), as the secondary sex ratio is only very slightly biased towards males (Cockburn and Double 2008). Hence, it is completely wrong to presume that female Superb Fairy-wrens, on average, gain a fitness benefit of 1.5 when they disperse, and it is likely that $\mathrm{C}_{\text {female }}$ is not greatly different to $\mathrm{C}_{\text {male }}$, and is likely to be low for both sexes.

Much more complicated, and openly admitted as a possibility by Grafen(1984), there are also a plethora of reasons why the estimate of B could be incorrect. Unfortunately, the comparison of reproductive success (RS) between pairs and groups tells us almost nothing about the value of B. Evidence that $\mathrm{RS}_{\text {group }}>$ $\mathrm{RS}_{\text {pair }}$ provides a perfect example of the difficulty in distinguishing causation from correlation. In the case of cooperative breeding, reproductive success could be enhanced because the extra provisioners augment the productivity of the breeding pair (hence B >0), as assumed by Brown (1975) and Grafen (1984). However, it is also likely that productive pairs or territories of Superb
Fairy-wrens will accumulate extra provisioners by virtue of their productivity, as reproductive success on the territory is normally a necessary condition for the presence of auxiliaries. In this case the value of B is moot, and requires more sophisticated analysis than a simple correlational approach.

Although this problem has been repeatedly mentioned (Brown et al. 1982), there have been few attempts to try and distinguish between the various alternatives. Experimental removals offer many advantages, although they suffer from three problems (Cockburn 1998). First, removal of a helper manipulates both their contribution to feeding but also the contribution they make to group size. Large non-reproductive groups enjoy enhanced foraging through reduced need to invest in detection of predators, so it may be that a positive effect of the presence of an extra bird could arise regardless of whether or not it incurs a benefit by providing care to the nestlings (passive benefits sensu Kokko et al. 2001). Hence, the helper would gain benefits (B) without paying a cost $(\mathrm{C})$, raising the question of why they bother to provision, unless they need to compensate other members of the group for costs that they impose, such as food sharing (active benefits sensu Kokko et al. 2001), or gain kin-selected benefits from doing so. Second, as we shall see later, it is possible that dominant birds would increase their efforts when helpers are not available, so immediate effects of help are obscured. Finally, and most pernicious, some cooperatively breeding species suffer massive social disruption when helpers are removed (Cockburn 1998). Unfortunately, the Superb Fairy-wren provides a classic example of these effects. Removal of the helper during the fertile period should increase the feeding by the dominant male because, in unassisted pairs, the female allocates more paternity to the dominant, so he is much more likely to be related to the offspring. In stark contrast to this prediction, this comparatively simple removal destroys the workings of the social group, and females are unwilling to proceed with reproduction if the workforce at their disposal changes suddenly at the start of the fertile period (Dunn and Cockburn 1996).

An alternative approach is to use paired comparisons between the same pair with and without auxiliaries. The application of this approach to Superb Fairy-wrens did not support an effect of help (Green et al. 1995) despite a correlation between productivity and the number of auxiliaries similar to that reported by Rowley (1964). However, Dickinson and Hatchwell (2004) have pointed out that such comparisons are difficult to interpret because they can only be constructed in groups where the numbers of helpers changes, and these are a biased subset of the available possibilities. Territories in which the number of auxiliaries increases are likely to have been initially more productive than average, whereas decline in the number of auxiliaries is most likely on unproductive territories. Both effects undermine the ability to use paired comparisons to tease apart the effect of help per se. Cockburn et al. (2008c) used an enormous dataset of Superb Fairy-wren observations to try and circumvent this problem. Initial statistical modelling suggested that productivity increased with rainfall, increased as the female moved from her first to subsequent breeding seasons, and increased with the number of helpers. Further dissection of the data supported the validity of the first two effects, but suggested that the helper effect was indeed most likely to be an artefact. Contrasts between cases where the group retained helpers, remained as an unassisted 
pair, acquired helpers, or lost helpers, suggested that any changes in productivity were dominated by environmental causes rather than the effect of help, so that benefits (B, measured as increased current productivity) is zero. Unfortunately the methods developed by Cockburn et al. (2008c) depend on a large amount of data, and frequent changes in whether helpers are present. These techniques have not yet been applied to other species of Malurus, although there are other datasets that might be adequate (Russell and Rowley 1993a, 2000).

\section{Do auxiliaries ever provide immediate benefits to the adults they assist?}

There have been two attempts to escape the difficulty of distinguishing an effect of group size from an effect of help in other species of fairy-wrens. Brooker and Rowley (1995) reported that reproductive success in Splendid Fairy-wrens increased sharply with the number of female helpers, but was unresponsive to the number of male helpers, which suggests that group size alone cannot be the source of the increased reproductive success in this species. This is surprising because there is no evidence that female auxiliaries provide more assistance than males (Russell and Rowley 1988). There is at least a small possibility that the result is an artefact that arises because females disperse to take up vacancies more frequently than males (Russell and Rowley 1993b). Territorial quality can be predicted by numerous habitat variables (Brooker and Rowley 1995) and if females were to use this information and be more likely to disperse from low-quality territories, the observed association could result. However, there is little evidence for this view because, as for male auxiliaries (Pruett-Jones and Lewis 1990), females appear to prefer to disperse when a vacancy becomes available (Russell and Rowley 1993b). An alternative explanation is that females provide higher quality care, perhaps by supplying better quality food (Colombelli-Négrel and Kleindorfer 2010), but at the moment the underpinning causes are not clear and require further investigation.

Kingma et al. (2010) used an alternative line of evidence to suggest an effect of help in the Purple-crowned Fairy-wren (M. coronatus). This species is of particular interest as it is the only member of Malurus in which extra-group fertilisations are rare, so $r$ is likely to be high (Kingma et al. 2009). In addition, and in sharp contrast to other species of Malurus, subordinates often provide no or little care. In other species the presence of individuals that do not provision has been successfully exploited to escape the usual inability to distinguish between the effects of group size and the additional provisioning by helpers (Davies and Hatchwell 1992; Magrath and Yezerinac 1997). In Purplecrowned Fairy-wrens, effect sizes for helper number were greater than those for group size, supporting the view that help rather than group size is of greatest importance. A caveat to this conclusion is that despite the greater effect size, the statistical strength of the relationship was much weaker for helper number than for group size (group size, $P=0.002$; helper number, $P=0.05)$. A more general conceptual difficulty is that subordinates may be better able to contribute food on territories of high quality, which would once again mean that the relationship has the potential to be an artefact. We will return to the question of why some individuals do not feed below.

\section{Future benefits of care}

The benefits that adults receive from help need not just result from immediate enhancement of the rearing of young from the broods that are provisioned by the helpers. Having additional food provided to the brood can allow the adults to reduce their own efforts and allow them to divert their energy to either maintenance or other fitness components. In particular, we need to be attentive to the possibility of load-lightening, which allows the recipients of help to improve their survival rather than their immediate fecundity. Hence benefits (B) could still be positive as a consequence of longer term, future indirect fitness effects on relatives (Mumme et al. 1989). Unfortunately, the difficulty of dissecting cause and correlation of survival data is even more difficult. Conditions that favour survival should increase both the accumulation of helpers on the territory and the survival of adults, so a positive association is the null expectation, regardless of any direct effect of help and load-lightening (Cockburn et al. 2008c).

Cockburn et al. (2008b) found that survival of the breeding female increased with the presence of male helpers in the Superb Fairy-wren, but that the survival of the dominant male did not. This was curious, because if anything, dominant males show stronger load-lightening than females, reducing care abruptly with the presence of helpers (Dunn and Cockburn 1996). This paradox was solved by the demonstration that females with helpers reduce their investment in eggs, affording them increased survival (Russell et al. 2007). The reduction in size of their nestlings is fully compensated by the extra food they receive because, despite load-lightening, groups still deliver more food to the nest. Nest translocations demonstrate this effect, as young hatching from eggs laid by females with helpers suffer when raised by unassisted pairs, whereas young from the large eggs laid by unassisted females become even heavier when reared by groups. It would be very informative to repeat this experiment in other species. Unlike the Superb Fairy-wren, in which the female is balancing her investment in eggs with decisions about how many eggs to lay, in some populations of its sister species, the Splendid Fairy-wren, there is almost no variation in clutch size (Russell and Rowley 1993a), which allows investment in eggs to be considered without confounding effects, although available data do not support the view that the presence of helpers increases survival in other species (Brooker and Rowley 1995).

\section{The importance of differences between the sexes}

Enhanced survival is not the only benefit that the breeding female can gain from helping behaviour in the Superb Fairywren. Females are much more likely to cuckold their partner completely, and hence rear only young sired by preferred extragroup sires, if they have helpers, apparently because helpers increase the certainty that some males will be available to provide care (Mulder et al. 1994; Dunn and Cockburn 1999). By contrast, the dominant males suffer a threefold cost. Not only are they cuckolded more by extra-group males (Mulder et al. 1994) but they lose some parentage to any helpers that are unrelated to the female (Cockburn 2004; Cockburn et al. 2008b), and if they are attractive, lose extra-group success through the parasitic behaviour of the helper during the dawn chorus, when females seek extra-group fertilisations (Double and Cockburn 2003; Cockburn et al. 2009). We have considered this conflict elsewhere, 
including in a companion paper in this issue (Dalziell and Cockburn 2008; Cockburn 2013; Cockburn et al. 2013), so will not reiterate our arguments about the evolution of this remarkable system here. However, this conflict draws our attention to the very different roles of males and females in fairy-wren society.

In addition to this conflict, we have pointed to the paradox that many females disperse to their doom in the Superb Fairy-wren, even leaving their natal territory if the dominant females dies during the period when competition among female dispersers for vacancies is most intense (Cockburn et al. 2003). However, in its sister species, the Splendid Fairy-wren, in which female helpers can be common, females appear to help the productivity of the group whereas male helpers do not (Brooker and Rowley 1995).

Even more remarkable results have emerged from a study of the one genetically monogamous fairy-wren, the Purple-crowned Fairy-wren, in which, unlike most fairy-wrens, auxiliary birds often do not provision young (Kingma et al. 2010). Kingma et al. (2011) extended their analysis to consider some of the other potential benefits that auxiliaries may gain from helping behaviour in order to explain this variation. In particular, they modelled feeding rates in relation to the prospect that birds would inherit the territory on which they live, as well as the degree of relatedness to the young, distinguishing between cases where the auxiliaries were related to both members of the breeding pair, just one of the breeding pair, or were unrelated to both members of the breeding pair. Individuals are least likely to inherit the vacancy when their promotion on the death of the dominant would cause them to pair with their mother and father, presumably because, as in any species where extra-group parentage is low, they would be exposed to the risk of incestuous mating. Kingma et al. (2011) argued that where individuals were not helping both their parents, they only provision when their prospects of inheritance are high. However, in addition to these effects, as in most species of Malurus, females are more likely to disperse and less likely to inherit than males, suggesting that the probability of inheritance cannot easily be distinguished from an effect of sex of the bird. Close inspection of the data leads us to hypothesise that most of the variation can be explained by recognising that female helpers always help when their mother is present, but do not do so when they are unrelated to the dominant female. The presence of the father does not affect feeding rates. We need better information on how females come to be helping an unrelated dominant female in order to understand why they do not feed in these circumstances, and also why they are tolerated when they provide no care.

We are thus left with extraordinary variation in outcomes between species. Females may either: (1) disperse, precluding any prospect of providing care; (2) remain philopatric, yet in some circumstances refuse to provide care or (3) remain philopatric and provide investment that is much more valuable to the recipients than the comparable care from males. This variation seems particularly well suited to teasing apart the nexus between philopatry and provisioning that lies at the heart of much discussion of cooperative breeding (Emlen 1997), yet often cannot be assessed critically for want of variation in the key behaviours. Further study of the Purple-crowned Fairy-wren will be rewarding, and it will be particularly valuable to assess the effect of females in Red-winged Fairy-wrens, in which philopatry and care by males and female helpers is equally prevalent (Russell and Rowley 2000; Brouwer et al. 2011).

\section{What determines the provisioning efforts of males?}

The sexual conflict that lies at the heart of fairy-wren society also draws attention to male behaviour. Two questions require consideration. First, why do dominant males reduce their contribution given that such load-lightening does not provide benefits via enhanced survival? Second, in contrast to females, males appear much less sensitive to the needs of the brood than females, ignoring the age of the chick and responding only moderately to clutch size (Dunn and Cockburn 1996; Russell et al. 2008).

Load-lightening could also allow investment in other activities. Green et al. (1995) speculated that males with helpers could devote more time to extra-group courtship, but subsequent analyses suggested that extra-group courtship during the breeding season is unlikely to enhance fitness greatly, as females base choice on male display before the breeding season begins (Green et al. 2000), and male mortality is concentrated in the winter rather than the breeding season itself. Hence, an alternative benefit remains elusive (Cockburn et al. 2008a).

An alternative hypothesis is that males are less likely to be caring for offspring in the presence of helpers (Mulder et al. 1994), and reduce their effort accordingly. There have been several attempts to distinguish this risk-of-cuckoldry hypothesis from the load-lightening hypothesis, but results have been confusing. In groups of a female and two males, removal of the auxiliary male during the fertile period was used to test whether the dominant male would increase his contribution, which might arise either because there was no load-lightening or because his confidence of parentage increased in the absence of a helper (Dunn and Cockburn 1996). Unfortunately, as we have already seen, this manipulation instead prompted the female to abandon that reproductive attempt, sometimes associated with her divorcing the home male. In a second manipulation, the helper was removed for $24 \mathrm{~h}$ during the period of parental care to see if the dominant male would increase his own care to compensate for the absence of helper, a prediction that would be compatible with the load-lightening hypothesis (Mulder and Langmore 1993). The dominant male failed to respond to this aspect of the removal, but attacked the helper violently for as long as 2 days when he was returned to the group. The attacks were so severe that the experiment was terminated for ethical reasons. Because this escalated violence is confined to the provisioning period, the experiment provides some of the best evidence for the hypothesis that helping behaviour is a consequence of coercion, and represents payment of rent (Mulder and Langmore 1993). It also lends support to the possibility that males may restrict their investment regardless of the need of the chicks, which supports the risk-ofcuckoldry hypothesis.

Partly motivated by these observations, MacGregor and Cockburn (2002) tried to manipulate parental provisioning using nestling playbacks. They did this by playing the very loud begging calls of old chicks to adults visiting the nest to feed young chicks, whose own begging was drowned out by the playback. Because adult females increase feeding with nestling age (and hence begging volume) they were predicted to increase provisioning. Males were also predicted to increase feeding rates 
if load-lightening explained the reduction of feeding by helpers, but this should not be the case if cuckoldry is the cause of the reduced care. The results were stark, but hardly consistent with the predictions. First, females ignored the manipulation completely, and continued to feed at the rate that would be expected for the 6-day-old chicks occupying the nest. In sharp contrast, all dominant and auxiliary males dramatically increased their feeding rates.

The failure of females to respond might reflect the use of a more complex suite of signals than begging alone in order to judge nestling need. The greater subtlety of female discrimination is suggested by the ability of females to reject chicks of the nestparasitic Horsfield's Bronze-Cuckoo (Chalcites basalis) but males can continue to provision for some time after the female has stopped feeding (Langmore et al. 2003). The dramatic response of males is, however, more difficult to explain, as it is starkly different to their failure to respond to nestling age in unmanipulated nests. The primary conclusion we can draw is that males typically work at a lower level than they can potentially achieve, although the playbacks were elevated for just $1 \mathrm{~h}$, and it is unclear whether males could maintain such exaggerated effort indefinitely.

The second feature of care by both subordinate and dominant males is insensitivity to the needs of the brood, despite the ability of males to respond that was revealed in the experiment by MacGregor and Cockburn (2002). There are three hypotheses that we believe require further exploration. First, it may be that the high risk of cuckoldry causes males to be cautious with nestling care, so that they feed at a rate that does not compromise survival and hence females are forced to adjust their own care in response to the needs of the brood, effectively preventing any exposure to elevated begging.

Second, male provisioning in most fairy-wrens is strongly influenced by a trade-off that cannot be adjusted in the manner used by other bird species. Males always feed the young hatched on their territory but also engage in extra-group courtship throughout the breeding season. Extra-group courtship involves frequent visits to all the females in their extended neighbourhood to perform characteristic furgling displays, and singing in the dawn chorus, where females consummate mating (Mulder 1997; Dalziell and Cockburn 2008; Cockburn et al. 2009). In many species of birds, courtship is reduced once provisioning begins, as courtship by males is stimulated by high levels of testosterone and testosterone suppresses parental behaviour. Male fairy-wrens cannot do this as they need to invest concurrently in parental care and extra-group courtship. This trade-off has been investigated in the Superb Fairy-wren by Peters and her colleagues (Peters 2002; Peters et al. 2000, 2001, 2002), who showed that the acquisition and maintenance of nuptial plumage depends on high levels of testosterone (Peters et al. 2000). Females prefer males that have been displaying for months before the start of the breeding season (Cockburn et al. 2008a), so some males need to maintain high levels of testosterone for very long period of time, both before and during the breeding season (Peters et al. 2001). Nonetheless, males varied in the testosterone levels they maintained. Experimental elevation of testosterone caused all males to increase courtship dramatically at the expense of care (Peters et al. 2002), suggesting that the level of testosterone is maintained at a level that permits both courtship and parental care (Peters 2002). It is plausible that this trade-off limits the capacity of males to express facultative variation in feeding rates, so females typically have primary responsibility for tuning effort to the needs of the brood.

Finally, sexual conflict theory has recently been applied to predict that where the likelihood of male care is jeopardised by the possibility of desertion, female choice might select for predictable and consistent provisioning from their male partners, so that they can reliably assess the additional effort that they will have to provide to ensure that the young thrive (Royle et al. 2010; Schuett et al. 2010). In support of this view, comparative analysis suggests that repeatability of provisioning is higher for the male parent than the female (Nakagawa et al. 2007; Schuett et al. 2010). Investigation of the causes of variation in the effort provided by individual males is likely to be particularly rewarding.

\section{Conclusions}

Cooperative breeding in all species of fairy-wren arises from natal philopatry, as predicted by the classic model of cooperative breeding. However, little else about fairy-wrens conforms to the standard model, because the expectation that helping behaviour will be directed to close kin often does not apply (Cockburn et al. 2013). Here we have shown that the complex outcomes from experiments in Superb fairy-wrens and surprising diversity among Malurus demand far greater effort in order to understand parent and offspring provisioning in these species. The effort is likely to illuminate general theory greatly. In some species, benefits derived from helping by auxiliary males have been monopolised by the female, but those benefits play out as increased survival and liberation to mate with extra-group males rather than as immediate enhancement of fecundity. Female behaviour among the genus is particularly variable, with different species differing in whether philopatry occurs or not and whether provisioning occurs or not. Remarkably, where female provisioning does occur, it appears to be more valuable than help by male young. Finally, fairy-wrens seem to be an unusually good system for examining recent predictions of parental care where there is sexual conflict between males and females.

\section{Acknowledgements}

Our research on fairy-wrens has been generously supported by a fellowship from the Swiss National Science Foundation to N. Margraf and several grants from the Australian Research Council to A. Cockburn. Our empirical research was greatly assisted by the Australian National Botanic Gardens (Canberra, $\mathrm{ACT}$ ), and many field assistants, most notably Helen Osmond. We are very grateful to Sjouke Kingma and Anne Peters for access to data and discussion of the remarkable behaviour of Purple-crowned Fairy-wrens, and Steve Pruett-Jones for constructive comments on the manuscript.

\section{References}

Boland, C. R. J., and Cockburn, A. (2002). Short sketches from the long history of cooperative breeding in Australian birds. Ети 102, 9-17. doi:10.1071/MU01039

Bradley, E., and Bradley, J. (1958). Notes on the behaviours and plumage of colour-ringed blue wrens. Ети 58, 313-326. doi:10.1071/MU958313

Brooker, M., and Rowley, I. (1995). The significance of territory size and quality in the mating strategy of the Splendid Fairy-wren. Journal of Animal Ecology 64, 614-627. doi:10.2307/5804 
Brouwer, L., van de Pol, M., Atema, E., and Cockburn, A. (2011). Strategic promiscuity helps avoid inbreeding at multiple levels in a cooperative breeder where both sexes are philopatric. Molecular Ecology 20, 4796-4807. doi:10.1111/j.1365-294X.2011.05325.x

Brown, J. L. (1975). 'The Evolution of Behavior.' (WW Norton: New York.)

Brown, J. L. (1987). 'Helping and Communal Breeding in Birds: Ecology and Evolution.' (Princeton University Press: Princeton, NJ.)

Brown, J. L., Brown, E. R., Brown, S. D., and Dow, D. D. (1982). Helpers: effects of experimental removal on reproductive success. Science $\mathbf{2 1 5}$, 421-422. doi:10.1126/science.215.4531.421

Cockburn, A. (1998). Evolution of helping behavior in cooperatively breeding birds. Annual Review of Ecology and Systematics 29, 141-177. doi:10.1146/annurev.ecolsys.29.1.141

Cockburn, A. (2004). Mating systems and sexual conflict. In 'Ecology and Evolution of Cooperative Breeding in Birds'. (Eds W. D. Koenig and J. L. Dickinson.) pp. 81-101. (Cambridge University Press: Cambridge, UK.)

Cockburn, A. (2006). Prevalence of different modes of parental care in birds. Proceedings of the Royal Society of London - B. Biological Sciences 273, 1375-1383. doi:10.1098/rspb.2005.3458

Cockburn, A. (2013). Cooperative breeding in birds: towards a richer conceptual framework. In 'Cooperation and its Evolution'. (Eds K. Sterelny, R. Joyce, B. Calcott and B. Fraser.) pp. 223-245. (MIT Press: Cambridge, MA.)

Cockburn, A., and Double, M. C. (2008). Cooperatively breeding Superb Fairy-wrens show no facultative manipulation of offspring sex ratio despite plausible benefits. Behavioral Ecology and Sociobiology 62, 681-688. doi:10.1007/s00265-007-0492-1

Cockburn, A., Osmond, H. L., Mulder, R. A., Green, D. J., and Double, M. C. (2003). Divorce, dispersal and incest avoidance in the cooperatively breeding Superb Fairy-wren Malurus cyaneus. Journal of Animal Ecology 72, 189-202. doi:10.1046/j.1365-2656.2003.00694.x

Cockburn, A., Osmond, H. L., and Double, M. C. (2008a). Swingin' in the rain: condition dependence and sexual selection in a capricious world. Proceedings of the Royal Society of London-B. Biological Sciences 275, 605-612. doi:10.1098/rspb.2007.0916

Cockburn, A., Osmond, H. L., Mulder, R. A., Double, M. C., and Green, D. J. (2008b). Demography of male reproductive queues in cooperatively breeding Superb Fairy-wrens Malurus cyaneus. Journal of Animal Ecology 77, 297-304. doi:10.1111/j.1365-2656.2007.01335.x

Cockburn, A., Sims, R. A., Osmond, H. L., Green, D. J., Double, M. C., and Mulder, R. A. (2008c). Can we measure the benefits of help in cooperatively breeding birds: the case of Superb Fairy-wrens Malurus cyaneus? Journal of Animal Ecology 77, 430-438. doi:10.1111/j.1365-2656. 2007.01351.x

Cockburn, A., Dalziell, A. H., Blackmore, C. J., Double, M. C., Kokko, H., Osmond, H. L., Beck, N. R., Head, M. L., and Wells, K. (2009). Superb Fairy-wren males aggregate into hidden leks to solicit extragroup fertilizations before dawn. Behavioral Ecology 20, 501-510. doi:10.1093/ beheco/arp024

Cockburn, A., Brouwer, L., Double, M., Margraf, N., and van de Pol, M. (2013). Evolutionary origins and persistence of infidelity in Malurus: the least faithful birds. Еmu 113, 208-217. doi:10.1071/MU12094

Colombelli-Négrel, D., and Kleindorfer, S. (2010). Video nest monitoring reveals male coloration-dependant nest predation and sex differences in prey size delivery in a bird under high sexual selection. Journal of Ornithology 151, 507-512. doi:10.1007/s10336-009-0480-5

Dalziell, A. H., and Cockburn, A. (2008). Dawn song in Superb Fairy-wrens: a bird that seeks extrapair copulations during the dawn chorus. Animal Behaviour 75, 489-500. doi:10.1016/j.anbehav.2007.05.014

Davies, N. B., and Hatchwell, B. J. (1992). The value of male parental care and its influence on reproductive allocation by male and female Dunnocks. Journal of Animal Ecology 61, 259-272. doi:10.2307/5319
Dickinson, J. L., and Hatchwell, B. J. (2004). Fitness consequences of helping. In 'Ecology and Evolution of Cooperative Breeding in Birds'. (Eds W. D. Koenig and J. L. Dickinson.) pp. 48-66. (Cambridge University Press: Cambridge, UK.)

Double, M. C., and Cockburn, A. (2003). Subordinate Superb Fairy-wrens (Malurus cyaneus) parasitize the reproductive success of attractive dominant males. Proceedings of the Royal Society of London - B. Biological Sciences 270, 379-384. doi:10.1098/rspb.2002.2261

Dunn, P. O., and Cockburn, A. (1996). Evolution of male parental care in a bird with almost complete cuckoldry. Evolution 50, 2542-2548. doi: $10.2307 / 2410724$

Dunn, P. O., and Cockburn, A. (1999). Extrapair mate choice and honest signaling in cooperatively breeding Superb Fairy-wrens. Evolution 53, 938-946. doi:10.2307/2640733

Dunn, P. O., Cockburn, A., and Mulder, R. A. (1995). Fairy-wren helpers often care for young to which they are unrelated. Proceedings of the Royal Society of London - B. Biological Sciences 259, 339-343. doi:10.1098/ rspb.1995.0050

Ekman, J., Hatchwell, B. J., Dickinson, J. L., and Griesser, M. (2004). Delayed dispersal. In 'Ecology and Evolution of Cooperative Breeding in Birds'. (Eds W. D. Koenig and J. L. Dickinson.) pp. 35-47. (Cambridge University Press: Cambridge, UK.)

Emlen, S. T. (1982). The evolution of helping. I. An ecological constraints model. American Naturalist 119, 29-39. doi:10.1086/283888

Emlen, S. T. (1997). Predicting family dynamics in social vertebrates. In 'Behavioural Ecology: An Evolutionary Approach'. 4th edn. (Eds J. R. Krebs and N. B. Davies.) pp. 228-53. (Blackwell Science: Oxford, UK.)

Grafen, A. (1984). Natural selection, kin selection and group selection. In 'Behavioural Ecology: An Evolutionary Approach'. 2nd edn. (Eds J. R. Krebs and N. B. Davies.) pp. 62-84. (Blackwell Scientific Publications: Oxford, UK.)

Green, D. J., Cockburn, A., Hall, M. L., Osmond, H., and Dunn, P. O. (1995). Increased opportunities for cuckoldry may be why dominant male fairy-wrens tolerate helpers. Proceedings of the Royal Society of London - B. Biological Sciences 262, 297-303. doi:10.1098/rspb. 1995.0209

Green, D. J., Osmond, H. L., Double, M. C., and Cockburn, A. (2000). Display rate by male fairy-wrens (Malurus cyaneus) during the fertile period of females has little influence on extra-pair mate choice. Behavioral Ecology and Sociobiology 48, 438-446. doi:10.1007/s002650000258

Higgins, P. J., Peter, J. M., and Steele, W. K. (Eds) (2001). 'Handbook of Australian, New Zealand and Antarctic Birds. Vol. 5: Tyrant-flycatchers to Chats.' (Oxford University Press: Melbourne.)

Kingma, S. A., Hall, M. L., Segelbacher, G., and Peters, A. (2009). Radical loss of an extreme extra-pair mating system. BMC Ecology 9, 15. doi:10.1186/1472-6785-9-15

Kingma, S. A., Hall, M. L., Arriero, E., and Peters, A. (2010). Multiple benefits of cooperative breeding in Purple-crowned Fairy-wrens: a consequence of fidelity? Journal of Animal Ecology 79, 757-768.

Kingma, S. A., Hall, M. L., and Peters, A. (2011). Multiple benefits drive helping behavior in a cooperatively breeding bird: an integrated analysis. American Naturalist 177, 486-495. doi:10.1086/658989

Kokko, H., Johnstone, R. A., and Clutton-Brock, T. H. (2001). The evolution of cooperative breeding through group augmentation. Proceedings of the Royal Society of London - B. Biological Sciences 268, 187-196. doi:10.1098/rspb.2000.1349

Komdeur, J. (1992). Importance of habitat saturation and territory quality for evolution of cooperative breeding in the Seychelles Warbler. Nature 358, 493-495. doi:10.1038/358493a0

Langmore, N. E., Hunt, S., and Kilner, R. M. (2003). Escalation of a coevolutionary arms race through host rejection of brood parasitic young. Nature 422, 157-160. doi:10.1038/nature01460 
MacGregor, N. A., and Cockburn, A. (2002). Sex differences in parental response to begging nestlings in Superb Fairy-wrens. Animal Behaviour 63, 923-932. doi:10.1006/anbe.2001.1991

Magrath, R. D., and Yezerinac, S. M. (1997). Facultative helping does not influence reproductive success or survival in cooperatively breeding White-browed Scrubwrens. Journal of Animal Ecology 66, 658-670. doi: $10.2307 / 5919$

Maguire, G. S., and Mulder, R. A. (2004). Breeding biology and demography of the Southern Emu-wren (Stipiturus malachurus). Australian Journal of Zoology 52, 583-604. doi:10.1071/ZO04043

Mulder, R. A. (1997). Extra-group courtship displays and other reproductive tactics of Superb Fairy-wrens. Australian Journal of Zoology 45, 131-143. doi:10.1071/ZO96041

Mulder, R. A., and Langmore, N. E. (1993). Dominant males punish helpers for temporary defection in Superb Fairy-wrens. Animal Behaviour 45, 830-833. doi:10.1006/anbe.1993.1100

Mulder, R. A., Dunn, P. O., Cockburn, A., Lazenby-Cohen, K. A., and Howell, M. J. (1994). Helpers liberate female fairy-wrens from constraints on extra-pair mate choice. Proceedings of the Royal Society of LondonB. Biological Sciences 255, 223-229. doi:10.1098/rspb.1994.0032

Mumme, R. L., Koenig, W. D., and Ratnieks, F. L. W. (1989). Helping behaviour, reproductive value, and the future component of indirect fitness. Animal Behaviour 50, 607-621.

Murphy, S. A., Legge, S. M., Heathcote, J., and Mulder, E. (2010). The effects of early and late-season fires on mortality, dispersal, physiology and breeding of Red-backed Fairy-wrens (Malurus melanocephalus). Wildlife Research 37, 145-155. doi:10.1071/WR09007

Nakagawa, S., Gillespie, D. O. S., Hatchwell, B. J., and Burke, T. (2007). Predictable males and unpredictable females: sex difference in repeatability of parental care in a wild bird population. Journal of Evolutionary Biology 20, 1674-1681. doi:10.1111/j.1420-9101.2007.01403.x

Peters, A. (2002). Testosterone and the trade-off between mating and paternal effort in extrapair-mating Superb Fairy-wrens. Animal Behaviour 64, 103-112. doi:10.1006/anbe.2002.3037

Peters, A., Astheimer, L. B., Boland, C. R. J., and Cockburn, A. (2000). Testosterone is involved in acquisition and maintenance of sexually selected male plumage in Superb Fairy-wrens, Malurus cyaneus. Behavioral Ecology and Sociobiology 47, 438-445. doi:10.1007/s0026500 50688

Peters, A., Astheimer, L. B., and Cockburn, A. (2001). The annual testosterone profile in cooperatively breeding Superb Fairy-wrens, Malurus cyaneus, reflects their extreme infidelity. Behavioral Ecology and Sociobiology 50, 519-527. doi:10.1007/s002650100403

Peters, A., Cockburn, A., and Cunningham, R. (2002). Testosterone treatment suppresses paternal care in Superb Fairy-wrens, Malurus cyaneus, despite their concurrent investment in courtship. Behavioral Ecology and Sociobiology 51, 538-547. doi:10.1007/s00265-002-0472-4
Pruett-Jones, S. G., and Lewis, M. J. (1990). Sex ratio and habitat limitation promote delayed dispersal in Superb Fairy-wrens. Nature 348, 541-542. doi: $10.1038 / 348541 \mathrm{a} 0$

Remeš, V., Matysiokova, B., and Cockburn, A. (2012). Long-term and largescale analyses of nest predation patterns in Australian songbirds and a global comparison of nest predation rates. Journal of Avian Biology 43, 435-444. doi:10.1111/j.1600-048X.2012.05599.x

Rowley, I. (1957). Cooperative feeding of young by Superb Blue Wrens. Emu 57, 356-357. doi:10.1071/MU957356

Rowley, I. (1964). The life history of the Superb Blue Wren. Emu 64, 251-297. doi:10.1071/MU964251

Rowley, I., and Russell, E. (1997). 'Fairy-wrens and Grasswrens: Maluridae.' (Oxford University Press: Oxford, UK.)

Royle, N. J., Schuett, W., and Dall, S. R. X. (2010). Behavioral consistency and the resolution of sexual conflict over parental investment. Behavioral Ecology 21, 1125-1130. doi:10.1093/beheco/arq156

Russell, E., and Rowley, I. (1988). Helper contributions to reproductive success in the Splendid Fairy-wren (Malurus splendens). Behavioral Ecology and Sociobiology 22, 131-140. doi:10.1007/BF00303548

Russell, E. M., and Rowley, I. (1993a). Demography of the cooperatively breeding Splendid Fairy-wren, Malurus splendens (Maluridae). Australian Journal of Zoology 41, 475-505. doi:10.1071/ZO9930475

Russell, E. M., and Rowley, I. (1993b). Philopatry or dispersal: competition for territory vacancies in the Splendid Fairy-wren, Malurus splendens. Animal Behaviour 45, 519-539. doi:10.1006/anbe.1993.1063

Russell, E., and Rowley, I. (2000). Demography and social organisation of the Red-winged Fairy-wren, Malurus elegans. Australian Journal of Zoology 48, 161-200. doi:10.1071/ZO99066

Russell, A. F., Langmore, N. E., Cockburn, A., Astheimer, L. B., and Kilner, R. M. (2007). Reduced egg investment can conceal helper effects in cooperatively breeding birds. Science 317, 941-944. doi:10.1126/ science. 1146037

Russell, A. F., Langmore, N. E., Gardner, J. L., and Kilner, R. M. (2008). Maternal investment tactics in Superb Fairy-wrens. Proceedings of the Royal Society of London - B. Biological Sciences 275, 29-36. doi:10.1098/rspb.2007.0821

Schodde, R., and Weatherly, R. (1982). 'The Fairy-wrens: a Monograph of the Maluridae.' (Lansdowne: Melbourne.)

Schuett, W., Tregenza, T., and Dall, S. R. X. (2010). Sexual selection and animal personality. Biological Reviews of the Cambridge Philosophical Society 85, 217-246. doi:10.1111/j.1469-185X.2009.00101.x

Tidemann, S. C. (1986). Breeding in three species of fairy-wrens (Malurus): do helpers really help? Ети 86, 131-138. doi:10.1071/ MU9860131

Van Bael, S., and Pruett-Jones, S. (2000). Breeding biology and social behaviour of the eastern race of the Splendid Fairy-wren Malurus splendens melanotus. Emu 100, 95-108. doi:10.1071/MU9831 